RHEUMATOID ARTHRITIS

\title{
Methotrexate and bridging glucocorticoids in early RA
}

Intensive treat-to-target strategies are widely recommended for the initial treatment of patients with early rheumatoid arthritis (RA), but questions remain about the ideal dosage and combination of drugs. The 16-week results of the care in early RA (CareRA) study suggest that, in a tight control setting, methotrexate with only a moderate step-down dose of glucocorticoids is no less effective for patients at high risk of disease progression than combinations of DMARD therapies with moderate or high step-down doses of glucocorticoids, with a more favourable short-term safety profile.

The prospective investigatorinitiated CareRA study focused on remission induction in patients with disease duration $\leq 1$ year who were naive to treatment with glucocorticoids or DMARDs and considered at high risk of progression on the basis of classical prognostic factors. Patients with erosive disease at enrolment were classified as high risk if they tested positive for autoantibodies (rheumatoid factor or anticitrullinated protein antibodies) or had a 28-joint disease activity score calculated with C-reactive protein level (DAS28[CRP]) >3.2; those with nonerosive disease were considered at high risk only if both these criteria were met.

290 of 380 patients enrolled in this multicentre trial were designated high risk and then randomly allocated to one of three treatment regimens, which were variations on the approach used in the Combination in RA (COBRA) trial and intended to reflect daily clinical practice. Patients in the 'COBRA classic' treatment group $(n=98)$ received $15 \mathrm{mg}$ methotrexate weekly, $2 \mathrm{~g}$ sulphasalazine daily and oral glucocorticoids at an initial dose of $60 \mathrm{mg}$ prednisone weekly on a stepdown scheme that tapered the dose in 7 weeks to $7.5 \mathrm{mg}$ prednisone weekly. Patients in the 'COBRA slim' group $(n=98)$ received $15 \mathrm{mg}$ methotrexate weekly and a lower step-down dose of glucocorticoids, initially $30 \mathrm{mg}$ tapered in 6 weeks to $5 \mathrm{mg}$ weekly. Finally, patients in the 'COBRA avant-garde' group $(n=94)$ received the DMARD combination of $15 \mathrm{mg}$ methotrexate weekly and $10 \mathrm{mg}$ leflunomide daily plus a weekly step-down scheme of oral glucocorticoids starting at $30 \mathrm{mg}$ prednisone weekly tapered in 6 weeks to $5.0 \mathrm{mg}$ weekly. In all groups, treatment was adjusted, from week 8 onwards, if patients failed to reach the target of DAS28(CRP) $\leq 3.2$.

A similar proportion of patients in each group (68.1-73.5\%) achieved remission, defined as DAS28(CRP) <2.6, at week 16 . Furthermore, the requirement for treatment adjustments was similar in all groups, and adverse events were reported by fewer patients in the 'slim' group (46.9\%) than the 'classic' or 'avant-garde' groups (61.2\% and 69.1\%, respectively). Thus, combination DMARDs do not seem to be more effective than methotrexate alone and, regardless of the DMARD combination used, a higher initial dose of glucocorticoids does not seem to confer additional benefit for the initial treatment of patients with RA and markers of poor prognosis.

\section{Sarah Onuora}

Original article Verschueren, P. et al. Methotrexate in combination with other DMARDs is not superior to methotrexate alone for remission induction with moderateto-high-dose glucocorticoid bridging in early rheumatoid arthritis after 16 weeks of treatment: the CareRA trial. Ann. Rheum. Dis. doi:10.1136/annrheumdis-2014-205489

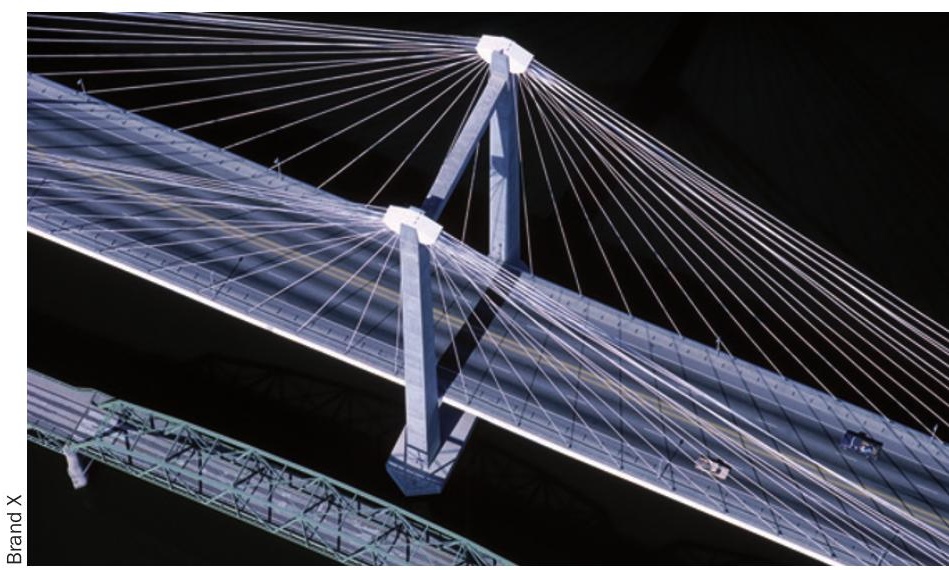

